\title{
Demand for Reserves and the Central Bank's Management of Interest Rates
}

\author{
Sébastien Kraenzlin and Martin Schlegel ${ }^{a}$
}

JEL-Classification: D40, E41, E43, E52

Keywords: Implementation of Monetary Policy, Money Demand, Fixed Rate Tender Auction, Repo, Switzerland

\section{Introduction}

Most central banks are nowadays committed to price stability. The implementation of monetary policy is prevalently done by management of an interest rate, with a short term market rate serving as operational target. The goal is to achieve a market interest rate in line with the central bank's desired level of interest rate (see for example BoE, 2012). In order to achieve this, the central bank needs the capability to manage the market interest rate accurately. Moreover, the reputation of a central bank among financial market participants depends among other things on the smoothness and predictability of the implementation of monetary policy.

This paper considers a model of a central bank with an interest rate as operational target. The means for achieving the goal are the quantity of reserves of banks with the central bank and the interest rate charged for lending to the banking system via open market operations. Most central banks provide reserves through auctions. The considered model is based on the fixed rate tender (volume tender) auction type, where the central bank announces the offered interest rate and allocates the reserves proportionally to the banks' bids.

In order for the interbank interest rate to be in line with the desired level of interest rate, the central bank has to estimate the amount of reserves banks

a Swiss National Bank (Money Market and Foreign Exchange), E-Mail: Sebastien.Kraenzlin@ snb.ch and Martin.Schlegel@snb.ch. The content of the publication is the sole responsibility of the authors and does not necessarily reflect the views of the Swiss National Bank. We gratefully acknowledge helpful comments from Nicole Braendle, Vincent Crettol, Karl Hug, Marco Huwiler, Thomas J. Jordan, Peter Kugler, Caesar Lack, Yvan Lengwiler, Ernst Lienhard, Christoph Meyer, Dewet Moser and Lidia Schmidt. 
demand at this rate. The level of reserves determines its scarcity and hence its price, i.e. the interest rate. If there are little reserves in the market, a cash taker is willing to pay a higher interest rate and hence the interbank interest rate will deviate from the desired level of interest rate. Banks have a demand for reserves because they are obliged to meet minimum reserve requirements and need reserves to settle transactions in the payment systems. The minimum reserve requirements have to be met on average in each maintenance period (see section 4.2). The central bank knows the reserve requirement of every bank and therefore also of the system as a whole. The banks assume that the central bank will provide the necessary reserves over the course of the maintenance period. Alternatively, the central bank could conduct an auction with full allotment. However, we suspect that a full allotment would in general result in excess reserves. Provided that the central bank does not offer a deposit facility, the market interest rate would be below the desired level of interest rate.

In normal times, central banks usually refrain from using the fixed rate tender auction with full allotment, since their information about required reserves and the payment system allows a superior provision of reserves and hence less volatile interest rates. Because of bidding dynamics in fixed rate tender auctions with no full allotment, the true demand for reserves is not directly observable for the central bank. ${ }^{1}$ Therefore, it has to estimate the true demand for reserves. This estimation is done under uncertainty because factors such as the government's balances at the central bank or banknotes in circulation influence the banks' level of reserves. If the central bank's estimation misses the true demand, the resulting interest rate on the interbank market will deviate from the desired level of interest rate. The deviation between these two interest rates and the deviation between total reserves and true demand allow us to estimate the demand curve for reserves. By using a variable rate auction framework - where banks submit the amount as well as the interest rate which they are willing to pay - the central bank can directly observe the demand curve for reserves. Cassola et al. (2009), for example, show that the bank's behavior in the European Central Bank's (ECB) one week auction reflects their cost of obtaining short-term funds elsewhere (i.e., in the interbank market). Furthermore they also show that the bank's bidding behavior reflects a strategic response to other bidders. Nevertheless several central banks prefer to use a fixed rate auction framework as the central bank can provide a very clear signal about the current monetary policy stance by setting the

1 See Breitung and Nautz (2001) and Nautz and Oechssler (2006) for a review and discussion on the overbidding phenomenon in the ECB System. 
interest rate in the auction (see for example EwerharT et al., 2012). This paper contributes to the existing literature by providing an empirical estimation of a demand curve for reserves in a fixed rate tender auction framework.

This paper uses data from Switzerland to estimate the demand curve and to test hypotheses about the demand for reserves. We find that the demand curve for reserves becomes steeper, because flexibility in the liquidity management diminishes towards the end of the maintenance period for minimum reserves. Furthermore, we find that the demand curve for reserves is steeper when the general interest rate level is high, because the opportunity cost of holding excess reserves is higher.

The paper is structured as follows: The following section introduces the institutional details of the implementation of monetary policy in Switzerland. The next sections introduce the model and discuss the different components that are required to estimate the demand curve. In the subsequent section, the estimated demand curve is used to test hypotheses on demand for reserves. The last section provides a discussion and some concluding remarks.

\section{Implementation of Monetary Policy at the SNB}

Since January 2000 the SNB announces a target range for the Swiss franc 3 -month Libor as operational target. In general the target range is 1 percentage point. In addition to announcing the target range, the SNB also specifies the aimed level of the 3-month Libor, which is usually the "middle of the target range". Since a 3-month rate depends on expectations of shorter term rates, the SNB allows fluctuations of the Libor within the target range. The target range gives the SNB the flexibility to react to other variables - like the risk premium in money market or movements in the exchange rate - without changing its formal monetary policy stance (see also BALTENSPERger et al, 2007).

The SNB manages the 3-month Libor through three main channels. Firstly, the announcement of the target range itself has an influence on the Libor. Secondly, since the Libor depends on expectations, the SNB's governing board manages the market expectation of future monetary policy actions. This is mainly done by public speeches and interviews. The third element is the SNB's open market operations.

The SNB's main open market operations are repo auctions. The auctions are conducted as a fixed rate tender (volume tender). In other words, the SNB announces the interest rate and maturity to its counterparties. The targeted volume, in turn, is not announced. The SNB's counterparties then have 10 
minutes to submit their bids, without knowing the bids of the other banks. Subsequently the SNB allocates the targeted amount. If total bids exceed the SNB's targeted allotment, each bank's bid is proportionally reduced. The interest rate, the allotment and the term offered depend on the SNB's specific monetary policy intentions.

In addition to its repo operations the SNB can also conduct fine-tuning operations. These operations mainly serve to counter undesired fluctuations in short term interest rates. Fine-tuning operations are conducted by placing quotes or (seldom) by accepting the banks' quotes in the repo interbank market. Fine-tuning operations are conducted only intermittently.

In the sample period the Swiss banking system is in a structural liquidity deficit. A structural liquidity deficit is a situation where the banking system is short of reserves versus the central bank, i.e. banks have to recur regularly to refinancing from the central bank. ${ }^{2}$

After the collapse of Lehman Brothers - in other words, at the height of the crisis - the SNB started to provide the banking system with generous amounts of liquidity among others by means of longer-term repo operations with full allotment and EURCHF swaps (in concert with the ECB, as well as the Polish and Hungarian central banks). ${ }^{3}$ From March 2009 to mid-2010 the SNB intervened in the foreign exchange market. By means of these interventions the SNB provided the banking system with liquidity to the amount of 191 billion Swiss francs. ${ }^{4}$ As a result the Swiss banking system has excess reserves and currently has net claims towards the SNB. In other words, it is currently in a structural liquidity surplus.

\section{The Model}

This section presents the setup to estimate the demand curve for reserves. We assume that the realized interest rate in the interbank market is a function of reserves. This relationship is the demand curve for reserves. Since the central bank does not know the exact demand when providing reserves at a given interest rate, demand needs to be estimated. Due to forecasting errors, the actual demand will casually deviate from the estimation. These errors will lead to an

2 Cf. Kraenzlin and Schlegel (2012).

3 Cf. SNB (2009) and SNB (2008).

4 See SNB (2011), p. 41.

5 See Danthine (2010a) and Danthine (2010b). 
inappropriate provision of reserves, which in turn causes a deviation of the market interest rate from the desired level of interest rate. The desired level of interest rate can either be the central bank's auction rate or an explicit target for the interbank rate. On the basis of these two deviations a demand curve for reserves can be constructed.

The estimation of the demand curve requires the observation of two points on the demand curve. In this paper, the central bank's auction rate is used as the desired level of interest rate. Hence, the first point is obtained from the auction rate and the reserves demanded at this rate. In a fixed rate tender auction the central bank announces the interest rate $\left(i_{C B}\right)$. Banks then submit their bids for reserves $\left(M_{b i d}\right)$. Strategic bidding behavior of the banks implies that the total bid amount does not necessarily correspond to the true demand $\left(D_{\text {true }}\right){ }^{6}$ As a consequence the bid amount needs to be adjusted to obtain the true demand. This leads to the first interest rate and reserves point $\left(i_{C B}, D_{\text {true }}\right)$. The second point is represented by the market interest rate $\left(i_{I B}\right)$ and the total reserves that banks hold at the central bank $\left(M_{\text {actual }}\right)$. With these two points at hand the demand curve for reserves is constructed. ${ }^{7}$ The model estimates the demand curve on a given day and assumes that there are no shifts in demand during the day. Figure 1 illustrates the model.

The subsequent section will discuss each component of the model in detail. First, the derivation and characteristics of the market interest rate and the total reserves will be discussed. Subsequently the auction setting and the estimation of the demand at the central bank's rate will be outlined.

\section{Description of the Variables}

In the following two sections, daily data from Switzerland is used to estimate the demand curve on the Swiss franc money market as well as to test the hypotheses on the demand curve. The sample period starts with the adoption of the new monetary policy framework by the Swiss National Bank (SNB) in January 2000

6 Ewerhart et al. (2012) outline that a fixed rate tender auction has the tendency to encourage overbidding, whereas Shino (2011) and Kraenzlin and Schlegel (2012) show that under certain circumstances strategic overbidding does not occur.

7 This model is valid if reserves from the central bank and the interbank market are perfect substitutes with respect to collateral and operational standards. Further, the model assumes that the frictions on the interbank market are negligible, i.e. banks with excess reserves are willing to lend reserves to banks with a refinancing need. 
Figure 1: The Demand Curve for Reserves

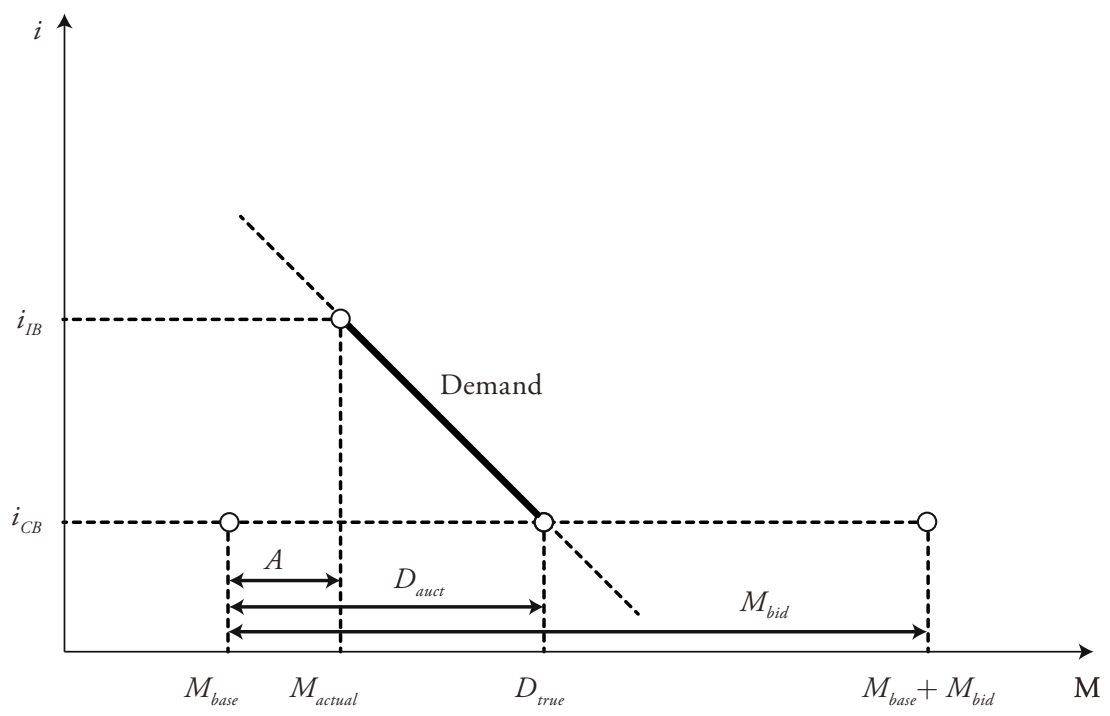

and ends in December 2006. ${ }^{8}$ The sample does not cover the financial crisis that started in August 2007, as the SNB has not conducted ON repo auctions on a regular basis since 2007 and hence no observations are available to estimate the model. The following section describes the framework for implementation of monetary policy of the SNB.

\subsection{Market Interest Rate $i_{I B}$}

The market interest rate $\left(i_{I B}\right)$ is represented by the volume weighted interest rate for transactions between banks in the secured interbank market. To avoid differences in pricing due to different maturities, the model considers market and central bank transactions with the same maturity and against the same collateral basket.

The representative secured interbank market in the Swiss franc is the Swiss repo system, where almost all interbank repo transactions in Swiss francs are

8 For a detailed description of the monetary policy framework of the SNB, see SNB (2004) and Jordan and Peytrignet (2007). 
conducted. ${ }^{9}$ However, one has to account for the eventuality that an interest rate differentiation may have been undertaken depending on the collateral delivered. Kraenzlin (2009) analyzed this for the Swiss franc repo market and came to the conclusion that an interest rate differentiation was done if certain collateral baskets had been chosen. To ensure comparability of the different interbank repo rate observations and the SNB auction rate, a rate adjustment is undertaken for the respective interest rate. ${ }^{10}$

The model uses the overnight $(\mathrm{ON})$ maturity. In the period of observation, ON interbank repo transactions took place on 1,746 working days. The ON repo market is the most liquid market segment of the Swiss franc repo market. From 2000 to 2006 the number of ON trades per working day varied between none and 124 . The traded volume varied accordingly between zero and 7.8 billion Swiss francs. On average the traded volume per working day lay at 1.9 billion Swiss francs. Deriving the volume weighted interest rate for each day leads to 1,746 market rate observations.

\subsection{Actual Reserves $M_{\text {actual }}$}

$M_{\text {actual }}$ denotes the total reserves that banks hold with the central bank. These reserves are used for the settlement of interbank payments like money market transactions. The level of reserves determines its scarcity and hence its price, i.e. the interest rate. If there are little reserves in the market, a cash taker is willing to pay a higher interest rate.

Since reserves are not remunerated banks try to minimize their reserve holdings once they meet the minimum reserve requirement and the desired precautionary reserves (excess reserves). In general, central banks provide a sufficient amount of reserves to the banking system, so that banks can achieve their reserves targets and the desired excess reserves.

In the short-run a central bank has to a large extent discretion on the total amount of reserves. However, other mandates of the central bank such as the issuance of banknotes and banking services provided to the government hamper a precise control of reserves. ${ }^{11}$ Banknotes in circulation are a very close substitute

9 For a detailed overview on Swiss repo platform and the development of the Swiss franc repo market see Jordan (2007) and KRAENZLin (2007).

10 The analysis by KraenzLin (2009) is based on data until June 2005. As the period of observation goes until December 2006 a least squares dummy variable regression was conducted for the missing period (July 2005 to December 2006). Regression results show the same pattern.

11 See Bindseil and Nyborg (2007) for a discussion on the autonomous liquidity factors and their impact on the implementation of monetary policy. 
for reserves. If, for example, a bank needs banknotes to fill an ATM, it withdraws banknotes from its reserve account with the central bank. An increase in banknotes in circulation will thus lower reserves and vice versa. On the other hand, if the government's balances with the central bank increases - for example because of tax payments - less reserves will be available to the banking system. These autonomous factors prevent the central bank from precisely controlling the reserves and impede an accurate management of interest rates.

The actual reserves $M_{\text {actual }}$ are derived by adding up the reserves balances of all banks that possess a sight deposit at the SNB. The value date of an $\mathrm{ON}$ repo transaction is $t+0$, i.e. an $\mathrm{ON}$ transaction will be settled on the same day as it had been traded. Hence, in the model the total sum of the reserve balances on the value date of the ON transaction will be taken as measure for $M_{\text {actual }}$.

\subsection{Central Bank Rate $i_{C B}$}

The central bank rate $\left(i_{C B}\right)$ denotes the interest rate the central bank announces in the fixed rate tender auction. Since the central bank acts as a monopolist in the market for reserves, banks are ultimately price takers. In practice, there are two different approaches prevalent: In the first, the central bank's interest rate $\left(i_{C B}\right)$ floats with the market rate $\left(i_{I B}\right)$. This implies that the central bank rate does not contain any information about the intended market interest rate. In this case, the central bank achieves the desired level of interest rate solely by providing the right amount of reserves to the market. The second approach uses $i_{C B}$ to signal the market the desired level of the market rate. The announcement of the interest rate in combination with the supply of reserves eventually leads to the achievement of the desired market rate. The first approach is used by the Federal Reserve (Fed). To achieve the desired federal funds rate, the Fed provides reserves to the banks at the interest rate determined in a variable tender auction. Since the interest rate banks have to pay is essentially a 'market rate', fluctuations in this rate contain no information about changes in the monetary policy stance. The second approach is employed for example by the Bank of England (BoE). The BoE provides reserves to the banks in a fixed rate tender auction at the official Bank Rate, its policy rate. The amount of reserves is chosen such that the overnight market rate is in line with the official Bank Rate and there is a flat money market yield curve up to one week, see BoE (2012). Fluctuations in the official Bank Rate signal a change in the monetary policy course. The SNB uses a mixed approach by applying the fixed rate tender and occasionally adjusting its auction interest rate (which is not its policy rate) to the market interest rate (see also section 5.2). 
Figure 2: Relative Importance of the Different Maturities for the SNB's Auctions

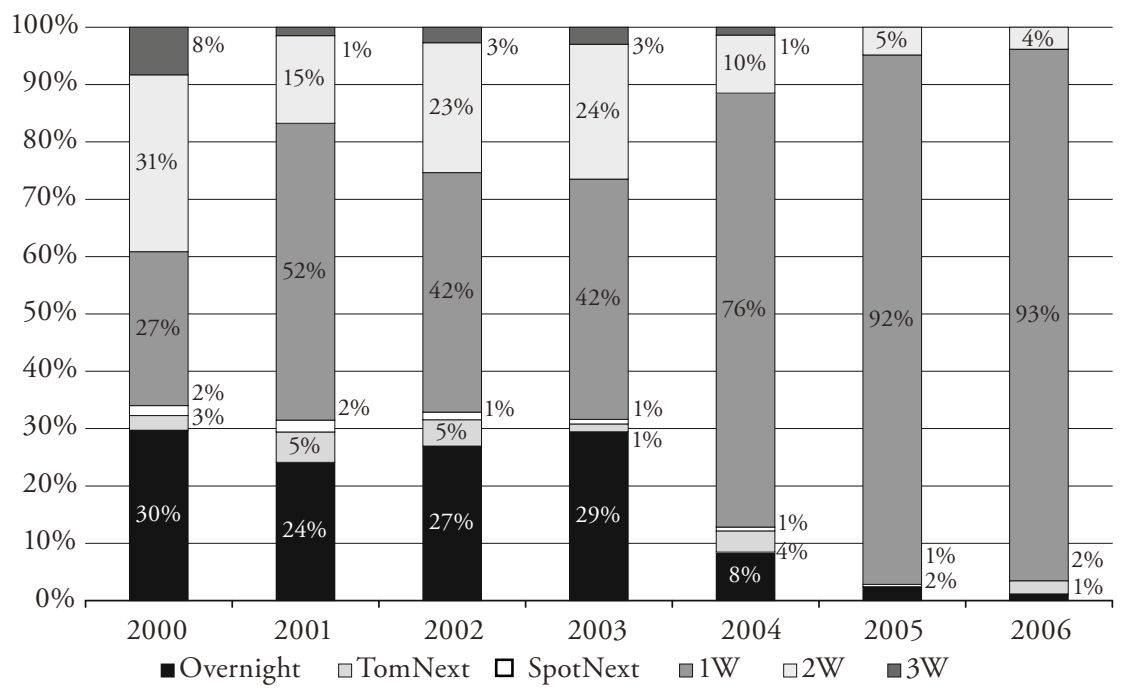

In the model, the central bank has discretion to let $i_{C B}$ float with the market rate (first approach) or to use $i_{C B}$ to signal the market the desired level of the market rate (second approach). In the second approach the interest rate $i_{C B}$ is therefore a signal bearer and eventually influences the demand curve for reserves exogenously. This implies a parallel shift of the demand curve. If the central bank does not anticipate the demand for reserves correctly or does not follow the market rate, the market rate $i_{I B}$ will deviate from central bank's rate $i_{C B}$.

In the sample period, the SNB has almost exclusively used repo operations to provide the market with reserves. The SNB conducts fixed rate tender auctions almost every working day at $9.00 \mathrm{am}$. When setting the interest rate in the auction, the SNB observes the trades and quoted rates in the repo market. In the sample period, the underlying maturity for SNB auctions varied. Figure 2 shows the use of the various maturity types for the SNB auctions. It is apparent that the ON maturity was used on average in 28\% of the cases from 2000 to 2003. Thereafter, the $\mathrm{ON}$ maturity was rarely used, while the 1-week maturity became more important. ${ }^{12}$ Overall the ON maturity auction was used 429 times $(20 \%$ of

12 Before 2004, the SNB's policy was to offer the banks a mix of maturities in its repo operations. After 2004 this policy was abandoned. 
all auctions conducted). In the period of observation the SNB changed its ON auction rate approximately 70 times. Since in the ON term there is a clear assignment of the reserves to the interest rate, the model considers only ON auctions.

The interest rate announced by the SNB in its daily auction will constitute the second interest rate measure for the estimation of the demand curve. Figure 3 plots the ON market rate with the rate charged by the SNB in its ON repo auctions.

\subsection{Base Reserves $M_{\text {base }}$}

$M_{\text {base }}$ refers to the amount of reserves that banks possess after repayment of the maturing repo operations but before the provision of the new reserves by the central bank. The central bank can for example control $M_{\text {base }}$ through outright purchases or sales of securities. If the central bank does not provide any reserves on a given day, $M_{\text {base }}$ will correspond to $M_{\text {actual }}$ and no demand curve can be estimated. In an environment where banks are short of reserves versus the central bank (structural liquidity deficit) base reserves $\left(M_{\text {base }}\right)$ are lower than the actual reserves $\left(M_{\text {actual }}\right)$ and the central bank has to provide reserves to the banks.

There are two possible ways to calculate $M_{\text {base }}$ in period $t$. One can either subtract the amount allotted $\left(A_{t}\right)$ in $t$ from the total reserves in the market $\left(M_{\text {actual, },}\right)$ in $t$. Alternatively one could take total reserves in the market in $t-1\left(M_{\text {actual, } t-1}\right)$ and subtract the operations that expire in $t\left(R_{t}\right)$ and add the changes in banknotes $\left(\Delta B_{t}\right)$ and government balances $\left(\Delta G_{t}\right)$. Both ways lead to the same $M_{b a s e, t}$.

$$
M_{\text {actual }, t}-A_{t}=M_{\text {base }, t}=M_{\text {actual }, t-1}-R_{t}+\Delta B_{t}+\Delta G_{t}
$$

Table 1 illustrates the liquidity planning of a central bank. In $t$, the central bank decides on how much reserves (2') to provide in $t+1$. By doing so it considers the maturing operations $\left(1^{\prime}\right)$, the expected change of banknotes in circulation $\left(3^{\prime}\right)$ and the expected change of the government's balances (4') as they affect reserves. The sum of (1') to (4') yields the estimated total change in reserves on the following day. In the example $M_{\text {base }}$ can be derived as follows. According to equation (1) this can either be done by subtracting (1') in $t+1$ from (6') in $t$ and adding the changes in banknotes and government balances or by subtracting (2') in $t+1$ from (6') in $t+1 . M_{\text {base }}$ amounts to 8,840 in the example. Unexpected changes in banknotes and government balances hamper the central bank's liquidity planning and therefore the management of interest rates. 
Figure 3: Comparison of the ON Market and Auction Rate
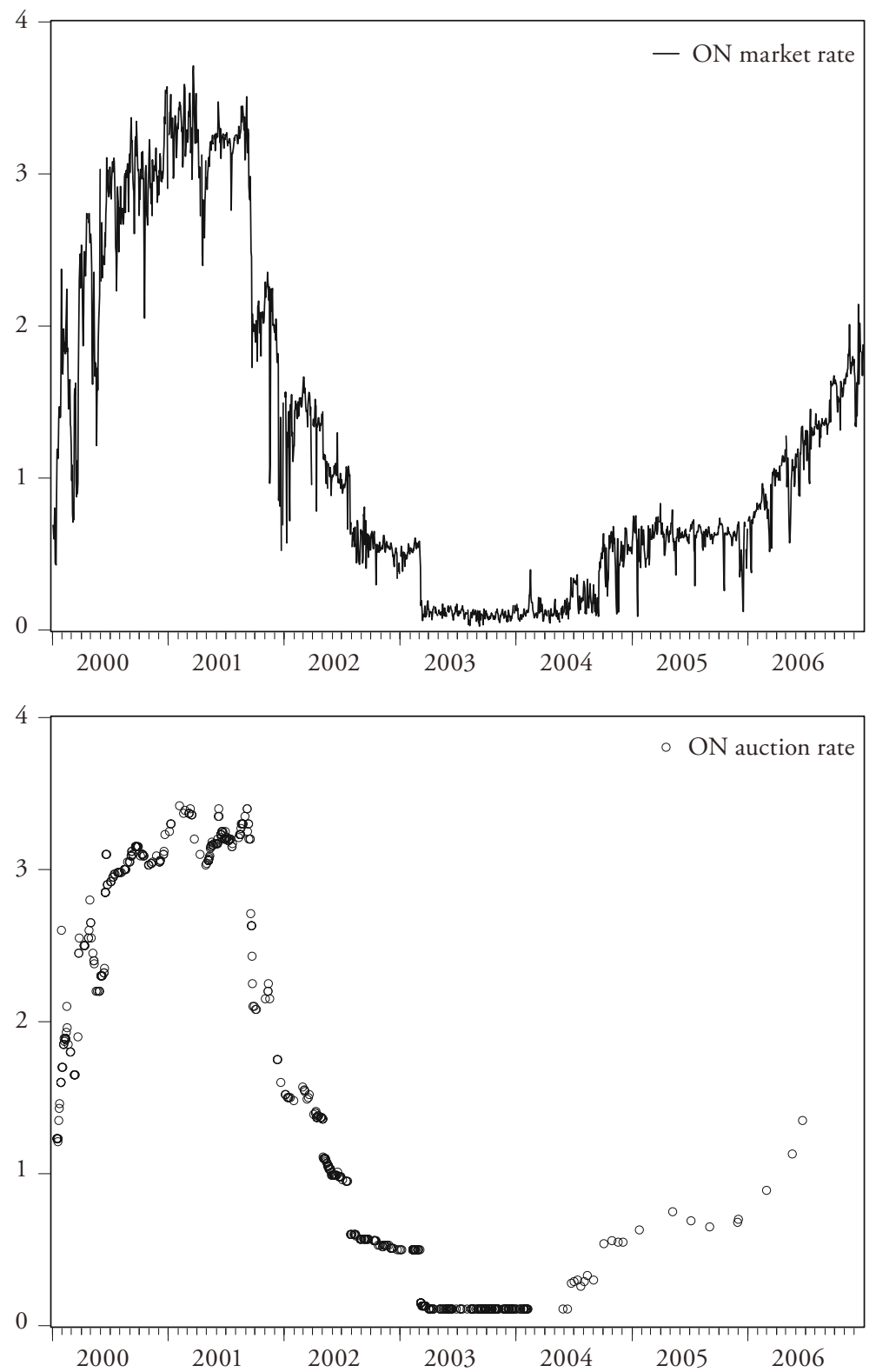
Table 1: The Liquidity Banking of a Central Bank

\begin{tabular}{lcc}
\hline & $t$ & $t+1$ \\
\hline maturing operations $R_{t}\left(1^{\prime}\right)$ & - & $-1,200$ \\
allotment $A_{t}\left(2^{\prime}\right)$ & - & 1,100 \\
\hline$\Delta$ banknotes in circulation $\Delta B_{t}\left(3^{\prime}\right)$ & - & 10 \\
$\Delta$ government balances $\Delta G_{t}\left(4^{\prime}\right)$ & - & 30 \\
\hline total changes $\left(5^{\prime}\right)$ & - & -60 \\
\hline$M_{\text {actual }}\left(6^{\prime}\right)$ & 10,000 & 9,940 \\
\hline
\end{tabular}

\subsection{Bid Amount $M_{b i d}$ and True Demand $D_{\text {true }}$}

In a fixed rate tender auction, the central bank announces the interest rate and banks subsequently submit their bids. After the closing of the auction the central bank allocates the planned amount proportionally to the banks' bids. The bid amount $\left(M_{b i d}\right)$ is the sum of all bids that banks tender. Because of strategic bidding behavior the bid amount does not necessarily correspond to the amount that banks want to obtain. When assessing the amount to tender, the liquidity manager at a bank must take the bank's refinancing needs for the given day, the expected allotment by the central bank and his expectations on the other banks' bidding behavior into account. Further, the liquidity manager will consider the spread between the central bank's rate and the expected market rate. If the central bank rate is below the market rate, refinancing at the central bank is more favorable and hence the bid amount higher. The allotment ratio is defined as $Q \equiv A / M_{b i d}$.

A crucial aspect in the model is to ascertain the expected allotment ratio $(E(Q))$ in order to derive the true demand. Thereby, the task is to predict the allotment ratio by modeling the way liquidity managers form their expectations. If a liquidity manager assesses the $Q$ correctly, he gets the desired amount.

Nautz and Oechssler (2006) assume an adaptive learning process under which the expected allotment ratio corresponds to the allotment ratio of the previous auction, i.e. $E_{t}\left(Q_{t}\right)=Q_{t-1}=A_{t-1} / M_{b i d, t-1}$, where $A$ is the amount allotted by the central bank. ${ }^{13}$ An informal survey of various liquidity managers suggests that the allotment ratio of the previous auction, the difference between the auction 
and the market interest rate as well as the size of the maturing repo operations should be taken into account. The interest rate spread is taken into account, as a bank will determine the amount to tender depending on the attractiveness of the central bank's rate relative to the prevailing market rate. According to the liquidity managers, the corresponding market rate of the previous day is used as proxy for today's market rate. One would expect that the bid amount is proportional to the maturing repo operations, and hence the allotment ratio unaffected. Empirical testing shows that the size of the maturing operations has a significant positive influence on the actual allotment ratio (see equation (2)). As the reserves provided in an auction correlate positively with the size of the maturing operations, liquidity managers compete more aggressively for the reserves if the maturing repo operations and hence the expected allotment is small. This is achieved by tendering more. The expected allotment ratio is modeled as an $\mathrm{AR}(1)$ process with two exogenous variables, the difference between the auction and the market interest rate as well as the size of the maturing repo operations (in billion Swiss francs)..$^{14,15}$ In order to get a time series for the allotment ratio without missing values, auctions with different maturities than the $\mathrm{ON}$ were taken into account. ${ }^{16}$ As the error structure is heteroskedastic and autocorrelated, Newey West standard errors were employed.

Using all these specifications leads to following estimates (with $t$-statistics in parentheses):

$$
\left.\hat{Q}_{t}=\underset{(7.03)}{0.277}+\underset{(7.76)}{0.39} Q_{t-1}+\underset{(2.69)}{0.022} \text { Maturing }+\underset{(4.01)}{0.35\left(i_{C B, t}\right.}-i_{I B, t-1}\right)
$$

The estimation results show that the allotment ratio is lower when the funds from the central bank are attractive compared to the funds obtained in the interbank market. This implies that banks bid more aggressively. This result is confirmed by Breitung and Nautz (2001). The fitted values of equation (2) represent the market participants' expected allotment ratio $E_{t}\left(Q_{t}\right)$. Game theoretically, if the

14 An AR(1) process is taken, as the estimated coefficients for additional lags of the dependent variable are not significant. The results in subsequent sections are not affected by the number of lags included in equation (2).

15 The maturing repo operations are defined as the sum of all operations that expire in $t$. This is sensible, as the maturing operations could, for instance, only be replaced by one auction and thus affect the allotment ratio in $t$.

16 If more than one maturity type auction had been conducted on a specific day, the observations were used in the following order: Overnight (ON), 1-week, 2-week, 3-week, TomNext $(\mathrm{TN}), \operatorname{Spot} \operatorname{Next}(\mathrm{SN})$. 
probability of getting less or more reserves than the true demand is strictly positive, the fixed rate tender auction can have no equilibrium, a unique equilibrium or multiple equilibria. ${ }^{17}$ Since this applies in the present case the proposed bidding rule is a candidate for a Nash-Equilibrium.

In the model, true demand $\left(D_{\text {true }}\right)$ represents the total amount of reserves that banks wish to hold at the central bank's interest rate. Usually the maturing repo operation is smaller than the total amount of reserves. This implies that a certain amount $\left(M_{\text {base }}\right)$ remains in the banking system (see section 4.4). To get the true demand at the central bank's rate, the reserves the banks wish to obtain in the auction $\left(D_{\text {auct }}=M_{\text {bid }} \cdot E(Q)\right)$ is added to the reserves that remains in the banking system $M_{\text {base }}$. In the model $M_{\text {base, }}$ is computed by subtracting the amount allotted $\left(A_{t}\right)$ by the central bank in $t$ from the total reserves $\left(M_{\text {actual },}\right)$ in $t$. The second reserves variable is thus derived as follows:

$$
D_{\text {true }}=M_{\text {base }}+D_{\text {auct }}=M_{\text {base }}+M_{\text {bid }} \cdot E(Q)
$$

\section{Results}

In this section, the slope of the demand curve is estimated with Swiss data. The crucial variables in estimating the model are the interest rate spread $\left(i_{C B}-i_{I B}\right)$ and the reserves gap $\left(D_{\text {true }}-M_{\text {actual }}\right)$. From these two variables the slope of the demand curve can be derived. Overall, 403 observations are available for the estimation of the slope. Furthermore, the hypotheses such as the slope pattern of the demand curve in the course of a maintenance period and the slope in different monetary regimes are analyzed. Finally, the question whether the SNB manages the market interest rates by providing the reserves needed and/or if it adjusts its rate $\left(i_{C B}\right)$ to be in line with the market rate $i_{I B}$ is investigated.

\subsection{Demand Curve}

Figure 4 depicts the interest rate spread $\left(i_{C B}-i_{I B}\right)$ versus the reserves gap $\left(D_{\text {true }}-M_{\text {actual }}\right)$. The observations in the upper left quadrant are associated with situations where the SNB's rate is above the market rate and hence demand for reserves smaller than the actual reserves. In the lower right quadrant, the SNB's rate is below the market rate and therefore demand for reserves higher than actual

17 See Ehrhart (2000) and Ehrhart (2001) for a game theoretical discussion of fixed rate tender auctions. 
Figure 4: Interest Rate Spread and Reserves Gap

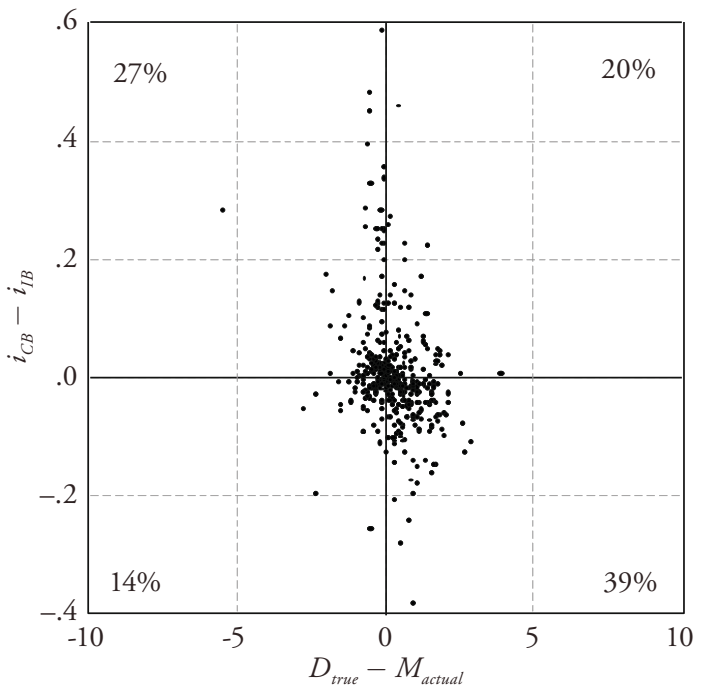

reserves. These two cases refer to a setting where the slope of the demand curve is negative. The observations in the upper right and lower left quadrants imply a positive slope of the demand curve. The interest rate spreads and reserves gaps in these quadrants may be attributed to inefficiencies in pricing on the interbank market or to shortfalls of the estimation of true demand by the model (see appendix). Overall 66\% of the observations lie in the upper-left and lower-right quadrant and hence imply a negative slope of the demand curve. The negative relationship is also underlined by the highly significant negative correlation coefficient of -0.27 .

The slope of the demand curve can be obtained by dividing the interest rate spreads by the reserves gaps. The mean of the divisions yields a slope of -14 basis points (bp) per billion Swiss francs. Assume for example that $\left(i_{C B}-i_{I B}\right)$ is $-10 b p$. To close the spread between the two interest rates, the SNB could - ceteris paribus - provide reserves such that actual reserves are approximately 700 million Swiss francs higher. Observing the Swiss franc money market, it can be ascertained that the slope coefficient and the implied relationship reflect market behavior and dynamics.

To perform further analysis it should be taken into account that by construction of the demand curve, the slope loses explanatory power when the interest rate 
spread, the reserves gap or both are small. Hence, when the central bank is successful in steering the money market, the estimation of the money demand curve is not well-founded. This "small triangle problem" can be tackled by weighting the slope observations according to their explanatory power. This explanatory power will be approximated by the square root of the product $\left(i_{C B}-i_{I B}\right) \cdot\left(D_{\text {true }}-M_{\text {actual }}\right)$. The subsequent analysis is thus based on weighted least squares (WLS) regressions.

\subsubsection{Slope Patterns during a Maintenance Period}

As mentioned previously, minimum reserve requirements force banks to hold a minimum amount of reserves. ${ }^{18}$ Since reserves have to be held on average over the maintenance period, every bank has the possibility to allocate its holdings to different times in the maintenance period. However, when the end of a maintenance period approaches, this flexibility diminishes. If there are excess reserves in the banking system towards the end of the maintenance period, banks try to reduce their holdings and thereby drive market rates down. In contrast, if the banks are short of reserves, they are willing to pay higher interest rates to fulfill the reserve requirements and thereby push market rates up. This reasoning leads to the hypothesis of a steeper demand curve towards the end of the maintenance period. Benito et al. (2006) empirically analyze the volatility of the Euro ON interest rate (EONIA) and show that the volatility of the EONIA is highest at the end of the maintenance period. Overall we expect that $\mathrm{ON}$ interest rates are very sensitive with respect to reserves on the last days of the maintenance period and thus tend to be particularly volatile on these days.

Figure 5 illustrates the results from the weighted least squares regression with dummy variables for the last five days of each maintenance period on the slope of the demand curve. Additionally the 3-month Libor is used to capture the general interest rate level. The values in Figure 5 represent the average slope on these days (with $t$-statistics in parentheses). ${ }^{19}$

As can be seen in the figure, the slope of the demand curve declines towards the end of the maintenance period. The slope is steepest on the second last day. This value is significantly different from the average slope. This null hypothesis

18 In Switzerland the minimum reserve requirement is computed monthly from a bank's shortterm liabilities at the end of the previous three months. Hence, the reserve requirement is known before the maintenance period. The maintenance periods run from the 20th of each month to the 19th of the following month. For more information on reserve requirements, see arts. 12ff. of the National Bank Ordinance as well as section 4.2.

19 The $t$-statistic is based on the null hypothesis that the slope on the specific day is not significantly different from the average slope of $-14 b p$ per billion CHF. 
Figure 5: Slope During the Last Days of the Maintenance Period

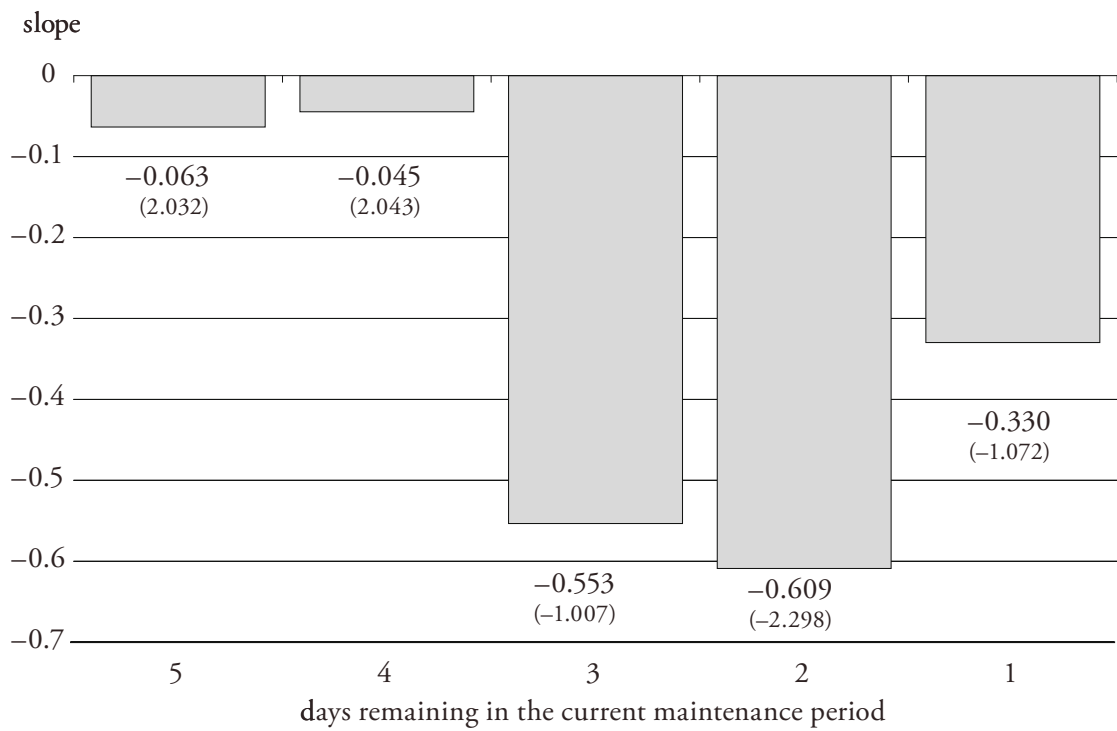

cannot be rejected for the third last and for the last day. Despite the theoretical prediction that the demand curve is steepest on the last day of the maintenance period, the model confirms the hypothesis of a steeper demand curve towards the end of the maintenance period.

A possible explanation for the steeper slope on the second last day could be, that liquidity managers do not want to wait to fulfill the reserve requirements until the last day of the maintenance period. Hence they try to reach the required reserves already on the second last day of the maintenance period. This result is in line with Thornton (2007). Thornton (2007) also describes the last two days of the maintenance period as interest rate inelastic.

\subsubsection{Slope of Demand and the Interest Rate Level}

The following section addresses the hypothesis whether the slope of the demand curve differs with the general interest rate level. The general interest rate levelmeasured by the 3-month Libor - determines the monetary policy stance. Since the sample period starts in 2000 and ends in 2006, a whole business cycle with the according tightening and loosening of monetary policy is taken into account. As opportunity costs of holding reserves are higher when interest rates are high (in 
absolute terms), one can generally expect that banks manage their reserves tighter. This implies a steeper demand curve when the general interest rate level is high. ${ }^{20}$

The hypothesis of a steeper demand curve is tested with the same regression as in section 5.1.1. The general interest rate level is captured by the 3 -month Libor. Due to the "small triangle problem", the weighted least squares approach is used. To account for the fact that the demand curve is steeper towards the end of the maintenance period, dummy variables were included for the last five days of each maintenance period. Regression results show that a 1 percentage point increase of the 3-month Libor is associated with a steepening of the demand curve of -0.0816 . This result is highly significant. It can thus be concluded, that a higher interest rate level is associated with a steeper demand curve for reserves.

\subsection{Role of $i_{C B}$ : Following or Guiding the Market?}

In this section, the role of the SNB's interest rate $\left(i_{C B}\right)$ is analyzed. The SNB declares to follow a mixed approach of management of interest rates and the management of reserves. ${ }^{21}$ However, the SNB does not commit to a specific rule. Basically, two approaches are possible: First, adjusting supply of reserves $\left(M_{\text {actual }}\right)$ with short term transactions such that the reference rate (3-month Libor) is in line with the operational target (a range in the target band for the 3-month Libor). The SNB's interest rate $\left(i_{C B}\right)$ charged in the short term transactions could then fluctuate with the corresponding market rate $\left(i_{I B}\right)$. A spread of the two rates is then closed by an adjustment of the central bank's rate $\left(i_{C B}\right)$. Second, the SNB chooses an intermediate reference rate, such as $i_{C B}$, which is believed to reflect the level at which the reference rate is at the level of the operational target. The SNB then provides reserves such that the market rate $\left(i_{I B}\right)$ is at the SNB's rate level $\left(i_{C B}\right)$. Under both approaches the central bank tries to avoid a spread of $i_{C B}$ and $i_{I B}$.

The behavior of the SNB can be analyzed by looking at situations where the market rate deviates from the SNB's rate. If the SNB follows the first approach, it will react to an observed deviation in $t$ by adjusting its rate $i_{C B}$ in $t+1$ in order to close the spread and hence follows the market. If the SNB employs the second approach, it will not adjust its interest rate, but rather adjust the amount of reserves $\left(M_{\text {actual }}\right)$ in $t+1$ such that the market interest rate $\left(i_{I B}\right)$ is expected to be in line with the SNB's rate $\left(i_{C B}\right)$ in $t+1$. Hence the SNB guides the market.

20 See Federal Reserve Bank (2007) for the relation between reserves and the interest rate level.

21 See SNB (2004), p.9. 
In both cases the SNB's reaction on the interest rate and/or reserves should lower the spread.

The question is addressed by a simple counting of the different cases. The 1 -week maturity is taken. This mainly because most observations in a row are available for the 1-week maturity. There are three caveats in this approach. First, because of the autonomous factors mentioned previously, the reserves cannot be precisely controlled by the SNB. However, with a daily average (absolute) change of 131 million Swiss francs in currency in circulation and 225 million Swiss francs in government balances, sufficient control over the actual reserves $M_{\text {actual }}$ is given. Second, a market rate cannot be controlled perfectly in practice. A deviation of some basis points has to be tolerated by the central bank. In the analysis below it is not taken into account if a deviation is big or small. ${ }^{22}$ Third, the SNB may expect an exogenous shift in demand such that the market rate and the SNB's rate converge without any measure.

Table 2 summarizes the SNB's behavior in the sample period. The first two rows represent reactions compatible with the approaches presented above. Given that the SNB's rate was below the market rate, the SNB increased reserves and its rate in $8 \%$ of the cases. In $17 \%$ of the cases it increased only the reserves and left the interest rate unchanged. When the SNB was expensive relative to the market, i.e. $i_{C B, t}-i_{I B, t}>0$, it decreased reserves and the interest rate in $3 \%$ of the cases. In $15 \%$ of the cases it lowered reserves and left the interest rate unchanged. Thus, we get the theoretically expected reaction in $44 \%$ of all observations. The two rows in the middle refer to cases where at least one variable is adjusted in the right direction. Whether the move of the other variable is rational depends on the size of the adjustment. For example, if the SNB's rate is below the market and is decreased further, the increase in reserves has to be big enough to compensate the initial spread and the new lowering of the SNB's interest rate. However, if the adjustment is smaller, this class of cases does not fall into the expected reaction category. A total of $15 \%$ of the observations lie in the two middle rows. The last two rows represent the cases where the intention of the SNB's reaction to the interest rate differential is not explainable by the normal approaches to steer short-term rates. For example, when observing a market rate above the SNB's rate, the SNB lowered its rate further and simultaneously reduced reserves. However, it should be taken into account, that the SNB might have intended to increase $M_{\text {actual }}$, but that at the end of the day $M_{\text {actual }}$ decreased due to changes in

22 The analysis was also done on the basis of threshold levels. However, the introduction of threshold levels does not significantly alter the results. 
the autonomous factors, such as banknotes in circulation or government balances. Further these observations could be due to special circumstances.

With this data at hand the question whether the SNB follows the management of interest rates or the management of reserves approach can be addressed. In $66 \%$ of the observations the SNB left its rate unchanged and in only $20 \%$ of the cases the SNB's interest rate was moved in order to close the spread. This evidence points to the prevalence of the second approach and hence a signal bearing function of the SNB's auction interest rate $i_{C B}$.

Table 2: The SNB's Reactions to an Interest Rate Spread

\begin{tabular}{lrrrrl}
\hline & \multicolumn{3}{c}{ SNB below market } & \multicolumn{2}{l}{ SNB above market } \\
reaction in $\mathrm{t}+1$ & \multicolumn{1}{c}{$i_{C B, t}-i_{I B, t}<0$} & \multicolumn{1}{c}{$i_{C B, t}-i_{I B, t}>0$} & reaction in $\mathrm{t}+1$ \\
\hline$M_{\text {actual }, t+1} \uparrow, i_{C B, t+1} \uparrow$ & 74 & $(8 \%)$ & 31 & $(3 \%)$ & $M_{\text {actual }, t+1} \downarrow, i_{C B, t+1} \downarrow$ \\
$M_{\text {actual }, t+1} \uparrow, i_{C B, t+1} \rightarrow$ & 160 & $(17 \%)$ & 139 & $(15 \%)$ & $M_{\text {actual }, t+1} \downarrow, i_{C B, t+1} \rightarrow$ \\
$M_{\text {actual }, t+1} \uparrow, i_{C B, t+1} \downarrow$ & 32 & $(3 \%)$ & 24 & $(3 \%)$ & $M_{\text {actual }, t+1} \downarrow, i_{C B, t+1} \uparrow$ \\
$M_{\text {actual }, t+1} \downarrow, i_{C B, t+1} \uparrow$ & 50 & $(5 \%)$ & 30 & $(3 \%)$ & $M_{\text {actual }, t+1} \uparrow, i_{C B, t+1} \downarrow$ \\
$M_{\text {actual }, t+1} \downarrow, i_{C B, t+1} \rightarrow$ & 172 & $(19 \%)$ & 139 & $(15 \%)$ & $M_{\text {actual }, t+1} \uparrow, i_{C B, t+1} \rightarrow$ \\
$M_{\text {actual }, t+1} \downarrow, i_{C B, t+1} \downarrow$ & 42 & $(5 \%)$ & 25 & $(3 \%)$ & $M_{\text {actual }, t+1} \uparrow, i_{C B, t+1} \uparrow$ \\
\hline
\end{tabular}

\section{Conclusion}

This paper presents a simple model of the demand for reserves. When the central bank provides reserves, the exact demand is not known and needs to be estimated. Due to forecasting errors, the demand for reserves will casually deviate from the estimated value. This deviation leads to an inappropriate provision of reserves, which in turn causes a deviation of the market interest rate from the desired level of interest rate. With these two deviations at hand, a demand curve for reserves is constructed.

The empirical construction of the demand curve with Swiss data yields an average slope of $-14 b p$ per billion Swiss francs. In addition we analyze if the slope of the demand curves is steeper towards the end of the maintenance period. If there are excess reserves in the banking system towards the end of the maintenance period, banks try to reduce their holdings and thereby drive market rates down. In contrast, if the banks are short of reserves, they are willing to pay higher 
interest rates to fulfill the reserve requirements and thereby push market rates up. A weighted least squares regression shows that the slope of the demand curve is steepest two working days before the end of the maintenance period. On previous days and on the last working day, the slope of the curve is less negative. A possible explanation for the steeper slope on the second last day could be, that liquidity managers do not want to wait to fulfill the reserve requirements until the last day of the maintenance period. Hence they try to reach the required reserves already on the second last day of the maintenance period. This result is in line with Thornton (2007). Thornton (2007) also describes the last two days of the maintenance period as interest rate inelastic.

As opportunity costs of holding excess reserves are (in absolute terms) higher when interest rates are high, one can generally expect that a high interest level is associated with a steeper demand curve. Regression results show that a 1 percentage point increase of the 3-month Libor is associated with a steepening of the demand curve of -0.0816 .

The Swiss National Bank does not commit to a specific rule for the management of the money market. The behavior of the SNB is analyzed by looking at situations where the market rate deviates from the SNB's rate. If the SNB interest rate follows the market rate, it will react to an observed deviation by adjusting its rate on the next day in order to close the spread. If the SNB's interest rate is a signal bearer, the SNB will not adjust its interest rate, but rather adjust the amount of reserves on the next day such that the market interest rate is expected to be in line with the SNB's rate. Hence the SNB guides the market. In both cases the SNB's reaction on the interest rate and/or reserves should lower the spread. In $66 \%$ of the observations the SNB left its rate unchanged and in only $20 \%$ of the cases the SNB's interest rate was moved in order to close the spread. This evidence points to the prevalence of the second approach and hence a signal bearing function of the SNB's auction interest rate.

\section{Appendix}

\section{Sources of Errors in the Estimation of Demand for Reserves}

As shown in section $5.1,34 \%$ of the observations imply a positive slope of the demand curve. This raises the question, why the model fails to estimate an adequate demand curve in certain circumstances. To address this question, one must distinguish between two cases. 
First, if the market rate is above the central bank's rate there are again two possible explanations for a positively sloped demand curve. Figure 6 depicts this situation. The first explanation involves the estimated true demand. When the demand forecast underestimates the true demand such that the estimated value is smaller than $M_{\text {actual }}$, the resulting demand curve will have a positive slope (see striped line). The second explanation concerns the market rate. When the observed market rate does not reflect the true market equilibrium rate such that it lies below the central bank rate, the estimated demand curve is again positively sloped (see dotted line).

Figure 6: Sources of Errors if $i_{I B}>i_{C B}$

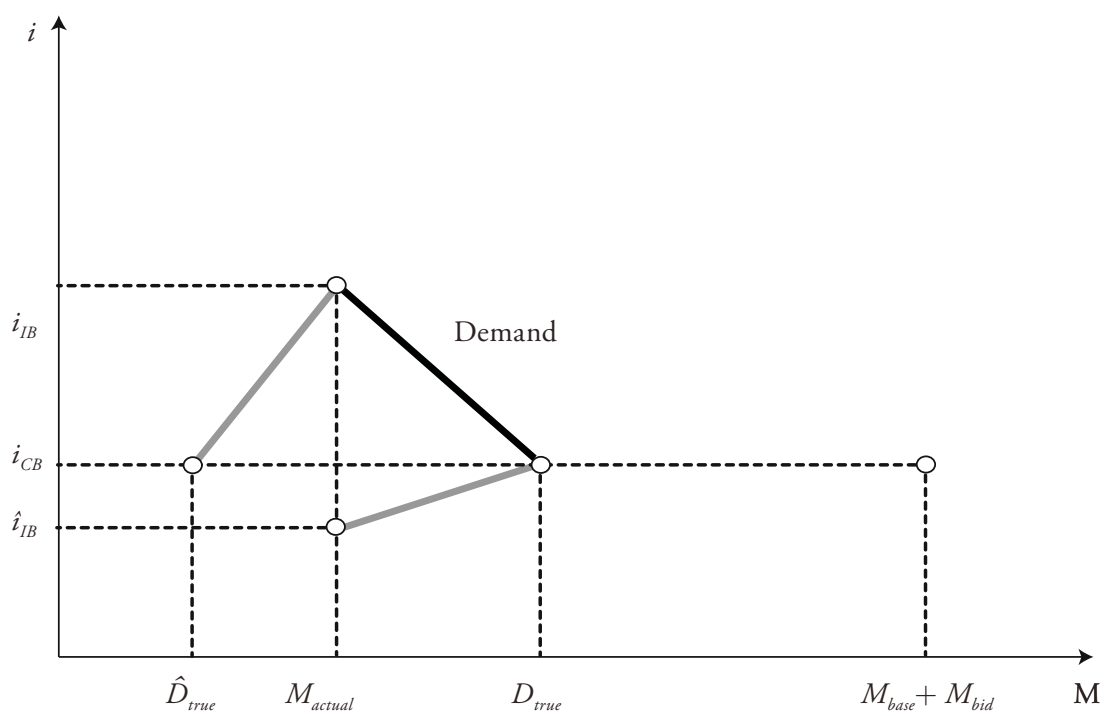

The second case is depicted in Figure 7. When the central bank's interest rate is above the market rate, there are again two possible explanations for a positive slope of the demand curve. If the model overestimated the true demand and lies above $M_{\text {actual }}$ or if the observed market rate is out of equilibrium such that it lies above the central bank's rate, the model predicts a positively sloped demand curve. 
Figure 7: Sources of Errors if $i_{I B}<i_{C B}$

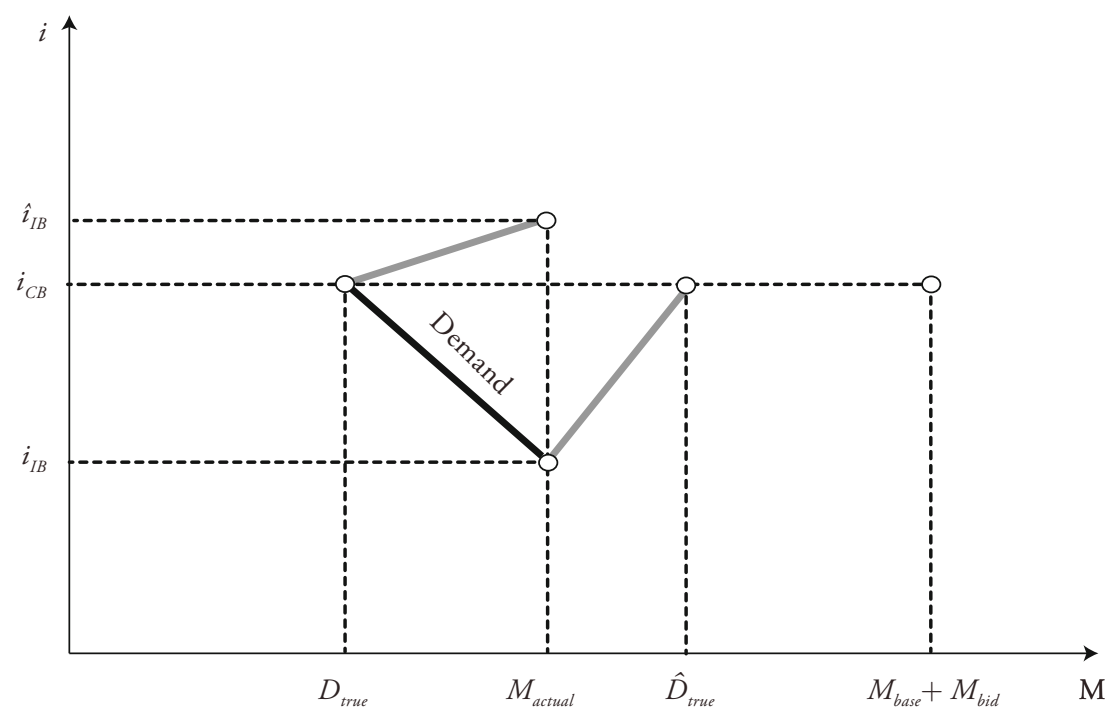

\section{References}

Baltensperger, Ernst, Philipp M. Hildebrand, and Thomas J. Jordan (2007), “The Swiss National Bank's Monetary Policy Concept - an Example of a 'Principle-Based' Policy Framework", Swiss National Bank Economic Studies 3.

Benito, Francis, Angel Leon, and Juan Nave (2006), "Modeling the Euro Overnight Rate", WP-AD 2006-11, Working Paper Serie AD from Instituto Valenciano de Investigaciones Economicas (Ivie).

Bindseil, Ulrich and Kjell G. Nyborg (2007), "Monetary Policy Implementation: A European Perspective", in Financial Markets and Institutions: A European Perspective, Oxford University Press.

Bank of England (2012), The Framework for the Bank of England's Operations in the Sterling Money Markets.

Breitung, Jorg, and Dieter Nautz (2001), "The Empirical Performance of the ECB's Repo Auctions: Evidence from Aggregated and Individual Bidding Data", Journal of International Money and Finance, 20, pp. 839-856. 
Cassola, Nuno, Ali Hortacsu, and Jakub Kastl (2009), “The 2007 Subprime Market Crisis Through the Lens of European Central Bank Auctions for Short-Term Funds", NBER Working Paper No. 15158.

Danthine, Jean-Pierre (2010a), "Introductory Remarks by Jean-Pierre Danthine at the Media News Conference", June 2010.

Danthine, Jean-Pierre (2010b), "Introductory Remarks by Jean-Pierre Danthine at the Media News Conference", December 2010.

European Central Bank (2000), "The Switch to Variable Rate Tenders in the Main Refinancing Operations”, ECB Monthly Bulletin, July, pp.37-42.

Ehrhart, Karl-Martin (2000), "A Well-Known Rationing Game”, Sonderforschungsbereich 504, Publication 01-36, Universität Mannheim.

Ehrhart, Karl-Martin (2001), "European Central Bank Operations: Experimental Investigation of the Fixed Rate Tender", Journal of International Money and Finance, 20, pp. 871-893.

Ewerhart, Christian, Nuno Cassola, and Natacha Valla (2012), "Overbidding in Fixed Rate Tenders: The Role of Exposure Risk", Journal of Banking and Finance, 36(2), pp. 539-549.

Federal Reserve Bank of New York (2007), "Domestic Open Market Operations During 2006", A Report prepared for the Federal Open Market Committee by the Markets Group of the Federal Reserve Bank of New York, February 2007.

Jordan, Thomas J., and Michel Peytrignet (2007), "The Path to Interest Rate Management and Inflation Forecasts", in The Swiss National Bank 19072007, pp. 255-271.

Jordan, Thomas J. (2007), „Das Repo-Geschäft in Schweizerfranken und die Innovation des geldpolitischen Instrumentariums der Schweizerischen Nationalbank", Aktuelle Rechtsprobleme des Finanzplatzes Schweiz, 2007.

Jordan, Thomas J., and Peter Kugler (2004), "Implementing Swiss Monetary Policy: Steering the 3M-Libor with Repo Transactions", Schweizerische Zeitschrift für Volkswirtschaft und Statistik, 140 (3), pp.381-393.

Kraenzlin, Sébastien, and Martin Schlegel (2012), "Bidding Behavior in the SNB's Repo Auctions", Journal of International Money and Finance, 31, 2012.

Kraenzlin, Sébastien (2009), "Interest Rate Setting On The Swiss Franc Repo Market", Swiss Journal of Economics and Statistics, 145 (3).

Kraenzlin, Sébastien (2007), "The Characteristics and Development of the Swiss Frank Repurchase Agreement Market", Financial Markets and Portfolio Management, 21 (2), pp. 241-261. 
Nautz, Dieter, and Jorg Oechssler (2006), "Overbidding in Fixed Rate Tenders - An Empirical Assessment of Alternative Explanations", European Economic Review, 50 (3), pp. 631-646.

Nautz, Dieter, and Jorg Oechssler (2003), "The Repo Auctions of the European Central Bank and the Vanishing Quota Puzzle", The Scandinavian Journal of Economics, 103 (2), pp. 207-220.

Shino, Junnosuke (2011), "A Positive Theory of Fixed-Rate Funds-Supplying Operations in an Accommodative Financial Environment", Bank of Japan Working Paper No.11-E-4, May 2011.

Swiss National Bank (2010), Annual Report of the Swiss National Bank 2010.

Swiss National Bank (2009), Annual Report of the Swiss National Bank 2009.

Swiss National Bank (2008), Annual Report of the Swiss National Bank 2008. Swiss National Bank (2004), The Swiss National Bank in Brief, December 2004.

Thornton, David (2007), "Open Market Operation and the Federal Funds Rate”, Federal Reserve Bank of St. Louis Review, 89 (6), pp. 549-570.

\section{SUMMARY}

The implementation of monetary policy is prevalently done by interest rate targeting with a short term market rate serving as operational target. The instruments for achieving the operational target are the provision of reserves and the interest rate charged in these transactions. This paper presents a model for the estimation of the demand curve for reserves, derived from the central bank's fixed rate tender auction and the interbank money market. Using data from Switzerland, the slope of the demand curve is estimated. Furthermore, properties of the demand curve such as the slope patterns in the course of a maintenance period and the slope in different monetary regimes are assessed. We find a steeper demand curve towards the end of the maintenance period and an increasing slope when the general interest rate level is high. Further, we investigate the role of the Swiss National Bank's (SNB) interest rate in the fixed rate tender auctions. There is evidence that the SNB uses its auction rate to guide the interbank market rate. 